\title{
Evaluating Features for \\ Identifying Japanese-Chinese Bilingual Synonymous Technical Terms from Patent Families
}

\author{
Zi Long \\ Takehito Utsuro \\ Grad. Sch. Sys. \& Inf. Eng., \\ University of Tsukuba, \\ Tsukuba, 305-8573, Japan
}

\author{
Tomoharu Mitsuhashi \\ Japan Patent \\ Information Organization, \\ 4-1-7, Tokyo, Koto-ku, \\ Tokyo, 135-0016, Japan
}

\author{
Mikio Yamamoto \\ Grad. Sch. Sys. \& Inf. Eng., \\ University of Tsukuba, \\ Tsukuba, 305-8573, Japan
}

\begin{abstract}
In the process of translating patent documents, a bilingual lexicon of technical terms is inevitable knowledge source. It is important to develop techniques of acquiring technical term translation equivalent pairs automatically from parallel patent documents. We take an approach of utilizing the phrase table of a state-of-theart phrase-based statistical machine translation model. First, we collect candidates of synonymous translation equivalent pairs from parallel patent sentences. Then, we apply the Support Vector Machines (SVMs) to the task of identifying bilingual synonymous technical terms. This paper especially focuses on the issue of examining the effectiveness of each feature and identifies the minimum number of features that perform as comparatively well as the optimal set of features. Finally, we achieve the performance of over $90 \%$ precision with the condition of more than or equal to $25 \%$ recall.
\end{abstract}

\section{Introduction}

For both high quality machine and human translation, a large scale and high quality bilingual lexicon is the most important key resource. Since manual compilation of bilingual lexicon requires plenty of time and huge manual labor, in the research area of knowledge acquisition from natural language text, automatic bilingual lexicon compilation have been studied. Techniques invented so far include translation term pair acquisition based on statistical co-occurrence measure from parallel sentences (Matsumoto and Utsuro, 2000), compositional translation generation based on an existing bilingual lexicon for human use (Tonoike et al., 2006), translation term pair acquisition by collecting partially bilingual texts through the search engine (Huang et al., 2005), and translation term pair acquisition from comparable corpora (Fung and Yee, 1998; Aker et al., 2013; Kontonatsios et al., 2014; Rapp and Sharoff, 2014).

Among those efforts of acquiring bilingual lexicon from text, Morishita et al. (2008) studied to acquire Japanese-English technical term translation lexicon from phrase tables, which are trained by a phrase-based SMT model with parallel sentences automatically extracted from parallel patent documents. Furthermore, based on the achievement above, Liang et al. (2011a) studied the issue of identifying Japanese-English synonymous translation equivalent pairs in the task of acquiring Japanese-English technical term translation equivalent pairs. Based on the technique and the results of identifying Japanese-English synonymous translation equivalent pairs in Liang et al. (2011a), Long et al. (2014) next studied how to identify Japanese-Chinese synonymous translation equivalent pairs from Japanese-Chinese patent families.

In the task of identifying Japanese-Chinese synonymous translation equivalent pairs from Japanese-Chinese patent families (Figure 1) studied in Long et al. (2014), this paper modifies some of the features studied in Long et al. (2014) and further focuses on the issue of examining the effectiveness of each feature. This paper especially identifies the minimum number of features that perform as comparatively well as the optimal set of features, where the most effective feature is discovered to be the rate of intersection in translation by the phrase table. Based on the evaluation results, we finally achieve the performance of over $90 \%$ precision with the condition of more than or equal to $25 \%$ recall.

\section{Japanese-Chinese Parallel Patent Documents}

Japanese-Chinese parallel patent documents are collected from the Japanese patent documents 


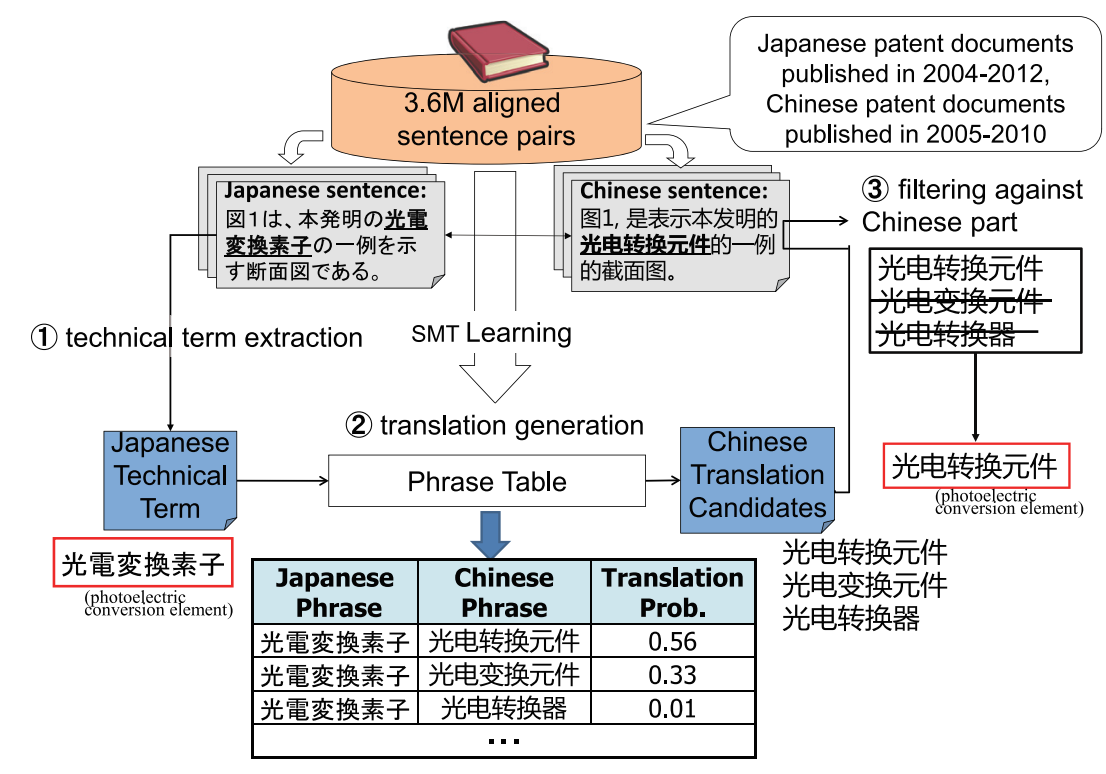

(a) Translation Estimation with a Phrase Table

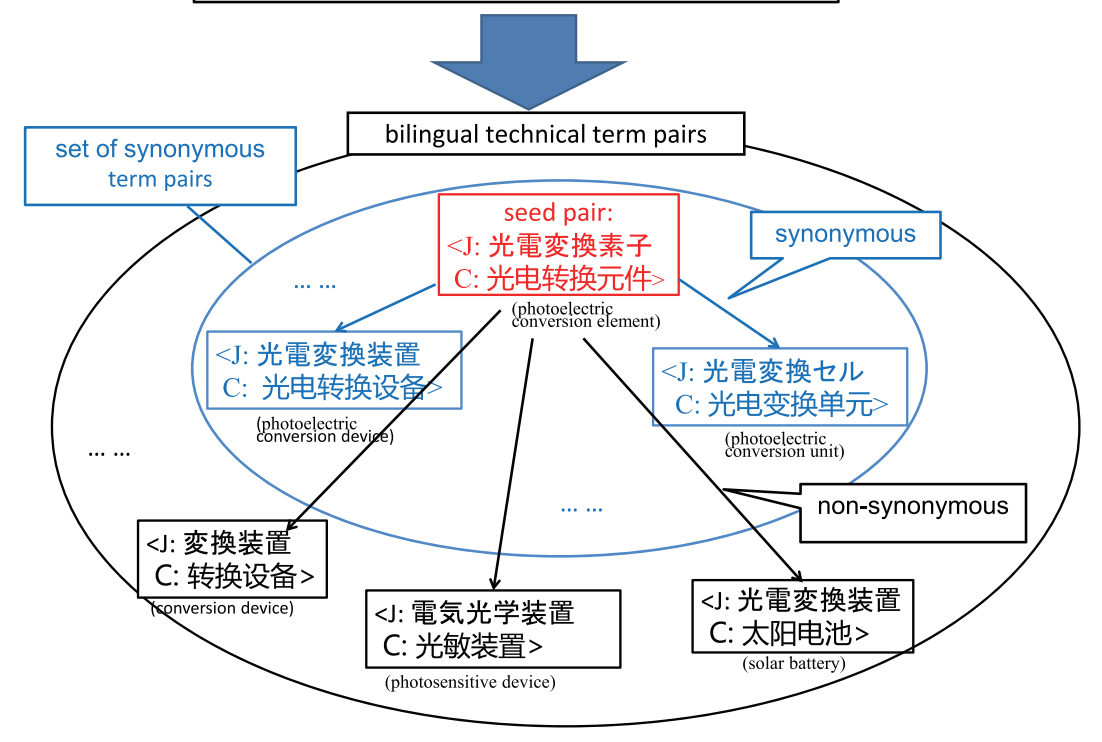

(b) Identifying set of synonymous term pairs

Figure 1: Framework of Identifying Japanese-Chinese Bilingual Synonymous Technical Terms from Patent Families

published by the Japanese Patent Office (JPO) in 2004-2012 and the Chinese patent documents published by State Intellectual Property Office of the People's Republic of China (SIPO) in 2005-2010. From them, we extract 312,492 patent families, and the method of Utiyama and Isahara (2007) is applied $^{1}$ to the text of those patent families, and Japanese and Chinese sentences are aligned. In this paper, we use $3.6 \mathrm{M}$ parallel patent sentences with the highest scores of sentence alignment ${ }^{2}$.

\footnotetext{
${ }^{1}$ We used a Japanese-Chinese translation lexicon consisting of about 170,000 Chinese head words.

${ }^{2}$ The maximum score of the method of Utiyama and Isahara (2007) is set to be 1.0, while the lower bound of its score is about 0.152 with the $3.6 \mathrm{M}$ parallel patent sentences.
}

\section{Phrase Table of an SMT Model}

As a toolkit of a phrase-based SMT model, we use Moses (Koehn et al., 2007) and apply it to the whole $3.6 \mathrm{M}$ parallel patent sentences. Before applying Moses, Japanese sentences are segmented into a sequence of morphemes by the Japanese morphological analyzer $\mathrm{MeCab}^{3}$ with the morpheme lexicon IPAdic ${ }^{4}$. For Chinese sentences, we examine two types of segmentation,

\footnotetext{
${ }^{3}$ http://mecab. sourceforge. net/

${ }^{4}$ http://sourceforge.jp/projects/ ipadic/
} 


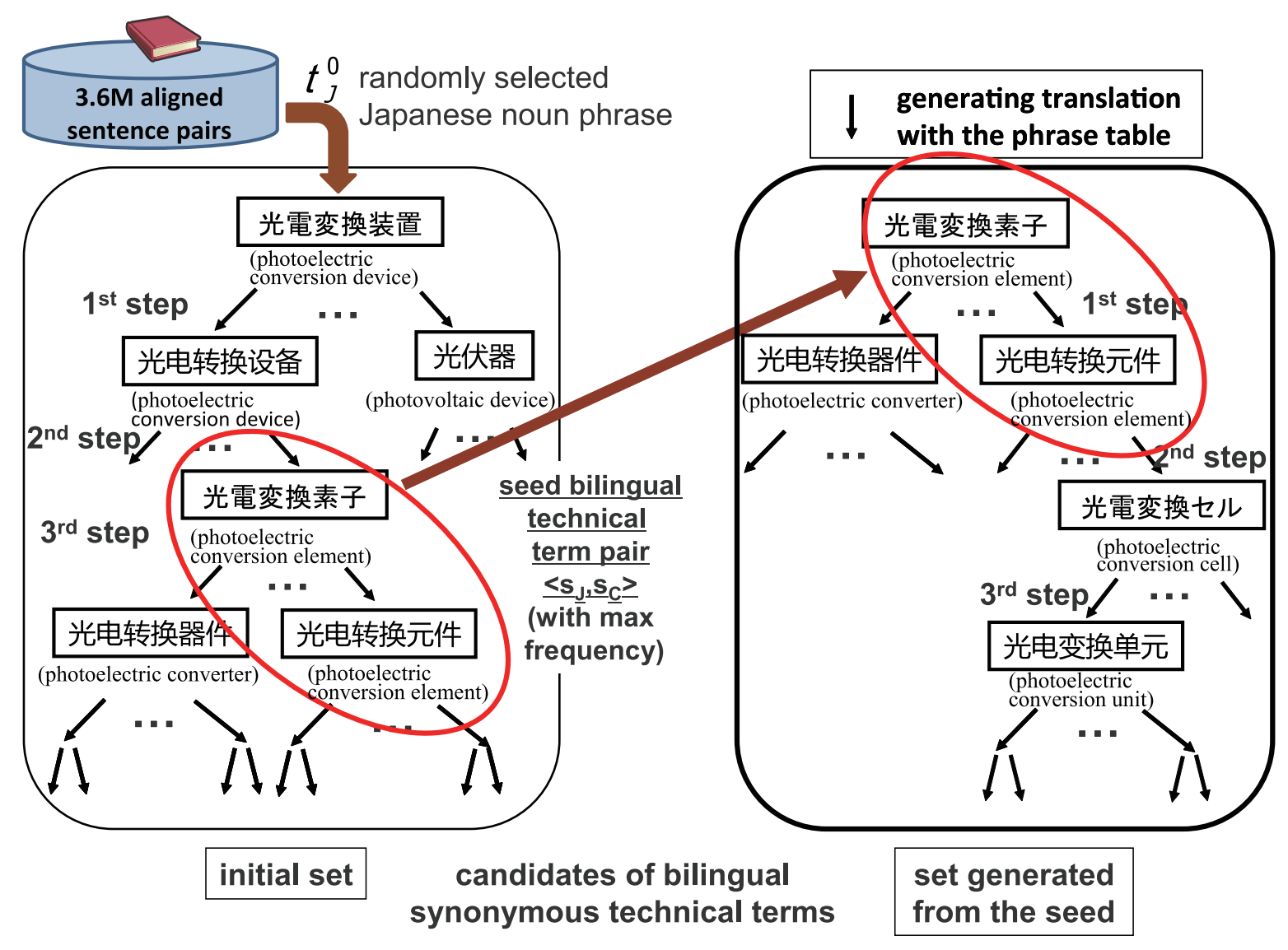

Figure 2: Developing a Reference Set of Bilingual Synonymous Technical Terms

i.e., segmentation by characters 5 and segmentation by morphemes ${ }^{6}$.

As the result of applying Moses, we have a phrase table in the direction of Japanese to Chinese translation, and another one in the opposite direction of Chinese to Japanese translation. In the direction of Japanese to Chinese translation, when Chinese side of parallel sentences are segmented by morphemes, we finally obtain $108 \mathrm{M}$ translation pairs with $75 \mathrm{M}$ unique Japanese phrases with Japanese to Chinese phrase translation probabilities $P\left(p_{C} \mid p_{J}\right)$ of translating a Japanese phrase $p_{J}$ into a Chinese phrase $p_{C}$. When Chinese sentences are segmented by characters, on the other hand, we obtain $274 \mathrm{M}$ translation pairs with 197M unique Japanese phrases. For each Japanese phrase, those multiple translation candidates in the phrase table are ranked in descending order of

\footnotetext{
${ }^{5} \mathrm{~A}$ consecutive sequence of numbers as well as a consecutive sequence of alphabetical characters are segmented into a token.

${ }^{6}$ Chinese sentences are segmented into a sequence of morphemes by the Chinese morphological analyzer Stanford Word Segment (Tseng et al., 2005) trained with Chinese Penn Treebank.
}

Japanese to Chinese phrase translation probabilities. In the similar way, in the phrase table in the opposite direction of Chinese to Japanese translation, for each Chinese phrase, multiple Japanese translation candidates are ranked in descending order of Chinese to Japanese phrase translation probabilities.

Those two phrase tables are then referred to when identifying a bilingual technical term pair, given a parallel sentence pair $\left\langle S_{J}, S_{C}\right\rangle$ and a Japanese technical term $t_{J}$, or a Chinese technical term $t_{C}$. In the direction of Japanese to Chinese, as shown in Figure 1 (a), given a parallel sentence pair $\left\langle S_{J}, S_{C}\right\rangle$ containing a Japanese technical term $t_{J}$, Chinese translation candidates collected from the Japanese to Chinese phrase table are matched against the Chinese sentence $S_{C}$ of the parallel sentence pair. Among those found in $S_{C}, \hat{t}_{C}$ with the largest translation probability $P\left(t_{C} \mid t_{J}\right)$ is selected and the bilingual technical term pair $\left\langle t_{J}, \hat{t}_{C}\right\rangle$ is identified. Similarly, in the opposite direction of Chinese to Japanese, given a parallel sentence pair $\left\langle S_{J}, S_{C}\right\rangle$ containing a Chinese technical term $t_{C}$, the Chinese to Japanese 
phrase table is referred to when identifying a bilingual technical term pair.

\section{Developing a Reference Set of Bilingual Synonymous Technical Terms}

When developing a reference set of bilingual synonymous technical terms (detailed procedure to be found in Long et al. (2014)), as illustrated in Figure 2, starting from a seed bilingual term pair $s_{J C}=\left\langle s_{J}, s_{C}\right\rangle$, we repeat the translation estimation procedure of the previous section in both Japanese-Chinese direction and Chinese-Japanese direction six times in total, and generate the set $C B P\left(s_{J}\right)$ of candidates of bilingual synonymous technical term pairs. Then, we manually divide the set $C B P\left(s_{J}\right)$ into $S B P\left(s_{J C}\right)$, those of which are synonymous with $s_{J C}$, and the remaining $N S B P\left(s_{J C}\right)$. As in Table 1, we collect 114 seeds, where the number of bilingual technical terms included in $S B P\left(s_{J C}\right)$ in total for all of the 114 seed bilingual technical term pairs is around 2,300 to 2,400, which amounts to around 21 per seed on average ${ }^{7}$. As shown in Figure 1 (b), to all of those bilingual term pairs, the procedure of identifying the synonymous sets is applied.

\section{Identifying Bilingual Synonymous Technical Terms by Machine Learning}

In this section, we apply the Support Vector Machines (SVMs) (Vapnik, 1998) to the task of identifying bilingual synonymous technical terms. In this paper, we model the task of identifying bilingual synonymous technical terms by the SVMs as that of judging whether or not the input bilingual term pair $\left\langle t_{J}, t_{C}\right\rangle$ is synonymous with the seed bilingual technical term pair $s_{J C}=\left\langle s_{J}, s_{C}\right\rangle$.

\subsection{The Procedure}

First, let $C B P$ be the union of the sets $C B P\left(s_{J}\right)$ of candidates of bilingual synonymous technical term pairs for all of the 114 seed bilingual technical term pairs. In the training and testing of the classifier for identifying bilingual synonymous technical terms, we first divide the set of 114 seed bilingual technical term pairs into 10 subsets. Here, for each $i$-th subset $(i=1, \ldots, 10)$, we construct the union $C B P_{i}$ of the sets $C B P\left(s_{J}\right)$

\footnotetext{
${ }^{7}$ We manually generate the reference set by discarding the bilingual pairs which are judged as not synonymous with the seed pair. The procedure of generating the whole reference sets took about 30 hours, i.e., about 3 seconds for judging a bilingual term pair on average.
}

of candidates of bilingual synonymous technical term pairs, where $C B P_{1}, \ldots, C B P_{10}$ are 10 disjoint subsets ${ }^{8}$ of $C B P$.

As a tool for learning SVMs, we use TinySVM (http://chasen.org/ taku/ software/TinySVM/). As the kernel function, we use the polynomial (1st order) kernel?. In the testing of a SVMs classifier, we regard the distance from the separating hyperplane to each test instance as a confidence measure, and return test instances satisfying confidence measures over a certain lower bound only as positive samples (i.e., synonymous with the seed). In the training of SVMs, we use 8 subsets out of the whole 10 subsets $C B P_{1}, \ldots, C B P_{10}$. Then, we tune the lower bound of the confidence measure with one of the remaining two subsets. With this subset, we also tune the parameter of TinySVM for trade-off between training error and margin. Finally, we test the trained classifier against another one of the remaining two subsets. We repeat this procedure of training / tuning / testing 10 times, and average the 10 results of test performance.

\subsection{Features}

Table 2 lists all the features used for training and testing of SVMs for identifying bilingual synonymous technical terms. Features are roughly divided into two types: those of the first type $f_{1}, \ldots, f_{6}$ simply represent various characteristics of the input bilingual technical term $\left\langle t_{J}, t_{C}\right\rangle$, while those of the second type $f_{7}, \ldots, f_{17}$ represent relation of the input bilingual technical term $\left\langle t_{J}, t_{C}\right\rangle$ and the seed bilingual technical term pair $s_{J C}=\left\langle s_{J}, s_{C}\right\rangle$

Among the features of the first type are the frequency $\left(f_{1}\right)$, ranks of terms with respect to the conditional translation probabilities $\left(f_{2}\right.$ and $\left.f_{3}\right)$, length of terms $\left(f_{4}\right.$ and $\left.f_{5}\right)$, and the number of times repeating the procedure of generating translation with the phrase tables until generating input terms $t_{J}$ and $t_{C}$ from the Japanese seed term $s_{J}$ $\left(f_{6}\right)$.

Among the features of the second type are identity of monolingual terms $\left(f_{7}\right.$ and $\left.f_{8}\right)$, edit distance of monolingual terms $\left(f_{9}\right)$, character bigram sim-

\footnotetext{
${ }^{8}$ Here, we divide the set of 114 seed bilingual technical term pairs into 10 subsets so that the numbers of positive (i.e., synonymous with the seed) / negative (i.e., not synonymous with the seed) samples in each $C B P_{i}(i=1, \ldots, 10)$ are comparative among the 10 subsets.

${ }^{9}$ We compare the performance of the 1 st order and 2nd order kernels, where we have almost comparative performance.
} 
Table 1: Number of Bilingual Technical Terms: Candidates and Reference of Synonyms

(a) With the Phrase Table based on Chinese Sentences Segmented by Morphemes

\begin{tabular}{|c|c|c|c|c|c|}
\hline & & $\begin{array}{r}\# \text { of } \\
\text { fo }\end{array}$ & $\begin{array}{l}\text { terms } \\
\text { ds }\end{array}$ & averag & er seed \\
\hline \multirow{2}{*}{$\begin{array}{c}\text { Candidates of Synonyms } \\
\qquad C B P\left(s_{J}\right)\end{array}$} & $\begin{array}{c}\text { included only } \\
\text { in the set (a) }\end{array}$ & 12,640 & \multirow{2}{*}{24,621} & 110.9 & \multirow{2}{*}{216.0} \\
\hline & $\begin{array}{l}\text { included in the intersection } \\
\text { of the sets (a) and (b) }\end{array}$ & 11,981 & & 105.1 & \\
\hline \multirow{2}{*}{$\begin{array}{l}\text { Reference of Synonyms } \\
\qquad \bigcup_{s_{J C}} S B P\left(s_{J C}\right)\end{array}$} & $\begin{array}{l}\text { included only } \\
\text { in the set }(a)\end{array}$ & 228 & \multirow{2}{*}{2,473} & 2.0 & \multirow{2}{*}{21.7} \\
\hline & $\begin{array}{l}\text { included in the intersection } \\
\text { of the sets (a) and (b) }\end{array}$ & 2,245 & & 19.7 & \\
\hline
\end{tabular}

(b) With the Phrase Table based on Chinese Sentences Segmented by Characters

\begin{tabular}{|c|c|c|c|c|c|}
\hline & & $\begin{aligned} \# \text { of b } \\
\text { for }\end{aligned}$ & $\begin{array}{l}\text { terms } \\
\text { ds }\end{array}$ & aver & er seed \\
\hline \multirow{2}{*}{$\begin{array}{l}\text { Candidates of Synonyms } \\
\qquad \bigcup_{s_{J}} C B P\left(s_{J}\right)\end{array}$} & $\begin{array}{l}\text { included only } \\
\text { in the set (b) }\end{array}$ & 6,358 & \multirow{2}{*}{17,478} & 55.8 & \multirow{2}{*}{153.3} \\
\hline & $\begin{array}{l}\text { included in the intersection } \\
\text { of the sets (a) and (b) }\end{array}$ & 11,120 & & 97.5 & \\
\hline \multirow{2}{*}{$\begin{array}{l}\text { Reference of Synonyms } \\
\qquad \bigcup_{s_{J C}} S B P\left(s_{J C}\right)\end{array}$} & $\begin{array}{l}\text { included only } \\
\text { in the set (b) }\end{array}$ & 287 & \multirow{2}{*}{2,318} & 2.5 & \multirow{2}{*}{20.3} \\
\hline & $\begin{array}{l}\text { included in the intersection } \\
\text { of the sets (a) and (b) }\end{array}$ & 2,031 & & 17.8 & \\
\hline
\end{tabular}

Table 4: Pairs of Features having No Significant Difference (5\% Significance Level) with Maximum Precision Features and their Evaluation Results $(\%)$

(a) Chinese sentences are segmented by morphemes

\begin{tabular}{|c|rcc|}
\hline feature & precision & recall & f-measure \\
\hline \hline$f_{15}+f_{16}$ & 85.6 & 25.4 & 39.2 \\
\hline$f_{9}+f_{16}$ & 86.8 & 24.9 & 38.7 \\
\hline$f_{13}+f_{14}+f_{16}$ & 86.8 & 24.8 & 38.6 \\
\hline
\end{tabular}

(b) Chinese sentences are segmented by characters

\begin{tabular}{|c|ccc|}
\hline feature & precision & recall & f-measure \\
\hline \hline$f_{9}+f_{15}$ & 87.4 & 25.4 & 39.3 \\
\hline
\end{tabular}

ilarity of monolingual terms $\left(f_{10}\right)$, rate of identical morphemes (in Japanese, $f_{11}$ ) / characters (in Chinese, $\left.f_{12}\right)$, string subsumption and variants for Japanese $\left(f_{13}\right)$, identical stem for Chinese $\left(f_{14}\right)$, rate of intersection in translation by the phrase table $\left(f_{15}\right)$, rate of intersection in translation by the phrase table for the substrings not common between the seed and a term $\left(f_{16}\right)$, and translation by the phrase tables $\left(f_{17}\right)$.

As we discuss in the next section, among all of those features, $f_{15}$ and $f_{16}$, which utilize the rate of intersection in translation by the phrase table, are the most effective, where we add $f_{16}$ in this paper to those studied in Long et al. (2014).

\subsection{Evaluating the Effectiveness of Features}

Table 3 shows the evaluation results for a baseline as well as for SVMs. As the baseline, we simply judge the input bilingual term pair $\left\langle t_{J}, t_{C}\right\rangle$ as synonymous with the seed bilingual technical term pair $s_{J C}=\left\langle s_{J}, s_{C}\right\rangle$ when $t_{J}$ and $s_{J}$ are identical, or, $t_{C}$ and $s_{C}$ are identical. When training / testing a SVMs classifier, we tune the lower bound of the confidence measure of the distance from the separating hyperplane in two ways: i.e., for maximizing precision and for maximizing F-measure. As shown in Table 3, when we use the set of features which maximize precision, we achieve higher precisions of $89.0 \%$ and $90.4 \%$ for morpheme-based segmentation and character-based segmentation, respectively, compared with when we use all of the proposed features $(86.5 \%$ and $89.0 \%)$ with the condition of more than or equal to $40 \% \mathrm{~F}$ measure $^{10}$. The sets of features which maximize precision are $f_{1 \sim 6}+f_{9 \sim 16}$ for morpheme-based

\footnotetext{
${ }^{10}$ Out of 655 (for morpheme-based segmentation) / 605 (for character-based segmentation) pairs which are correctly judged as synonymous with the seed pair by SVM , 197 $(30.1 \%) / 161(26.6 \%)$ are not judged as synonymous by the baseline method, i.e., neither the Japanese term nor the Chinese term is identical to that of the seed pair. On the other hand, out of 986 (for morpheme-based segmentation) / 927 (for character-based segmentation) pairs which are correctly judged as synonymous by the baseline method, 458 (46.5\%)/ $444(47.9 \%)$ are judged as synonymous with the seed pair by SVM, while the rests are not judged as synonymous by SVM.
} 
Table 2: Features for Identifying Bilingual Synonymous Technical Terms by Machine Learning

\begin{tabular}{|c|c|c|c|}
\hline class & & feature & $\begin{array}{c}\text { definition ( where } X \text { denotes } J \text { or } C \text {, } \\
\text { and }\left\langle s_{J}, s_{C}\right\rangle \text { denotes the seed bilingual technical term pair ) }\end{array}$ \\
\hline \multirow{6}{*}{$\begin{array}{l}\text { features } \\
\text { for } \\
\text { bilingual } \\
\text { technical } \\
\text { terms } \\
\left\langle t_{J}, t_{C}\right\rangle\end{array}$} & $f_{1}:$ & frequency & $\begin{array}{l}\text { log of the frequency of }\left\langle t_{J}, t_{C}\right\rangle \text { within the whole parallel patent } \\
\text { sentences }\end{array}$ \\
\hline & $f_{2}:$ & rank of the Chinese term & $\begin{array}{l}\text { given } t_{J}, \log \text { of the rank of } t_{C} \text { with respect to the descending order } \\
\text { of the conditional translation probability } \mathrm{P}\left(t_{C} \mid t_{J}\right)\end{array}$ \\
\hline & $f_{3}:$ & rank of the Japanese term & $\begin{array}{l}\text { given } t_{C}, \log \text { of the rank of } t_{J} \text { with respect to the descending order } \\
\text { of the conditional translation probability } \mathrm{P}\left(t_{J} \mid t_{C}\right)\end{array}$ \\
\hline & $f_{4}:$ & $\begin{array}{l}\text { number of Japanese charac- } \\
\text { ters }\end{array}$ & number of characters in $t_{J}$ \\
\hline & $f_{5}:$ & $\begin{array}{l}\text { number of Chinese charac- } \\
\text { ters }\end{array}$ & number of characters in $t_{C}$ \\
\hline & $f_{6}:$ & $\begin{array}{l}\text { number of times generating } \\
\text { translation by applying the } \\
\text { phrase tables }\end{array}$ & $\begin{array}{l}\text { the number of times repeating the procedure of generating transla- } \\
\text { tion by applying the phrase tables until generating } t_{C} \text { or } t_{J} \text { from } \\
s_{J} \text {, as in } s_{C} \rightarrow \cdots \rightarrow t_{J} \rightarrow t_{C} \text {, or, } s_{J} \rightarrow \cdots \rightarrow t_{C} \rightarrow t_{J}\end{array}$ \\
\hline \multirow{11}{*}{$\begin{array}{l}\text { features } \\
\text { for the } \\
\text { relation } \\
\text { of } \\
\text { bilingual } \\
\text { technical } \\
\text { terms } \\
\left\langle t_{J}, t_{C}\right\rangle \\
\text { and the } \\
\text { seed } \\
\left\langle s_{J}, s_{C}\right\rangle\end{array}$} & $f_{7}:$ & identity of Japanese terms & returns 1 when $t_{J}=s_{J}$ \\
\hline & $f_{8}:$ & identity of Chinese terms & returns 1 when $t_{C}=s_{C}$ \\
\hline & $f_{9}:$ & $\begin{array}{l}\text { edit distance similarity of } \\
\text { monolingual terms }\end{array}$ & $\begin{array}{l}f_{9}\left(t_{X}, s_{X}\right)=1-\frac{E D\left(t_{X}, s_{X}\right)}{\max \left(\left|t_{X}\right|,\left|s_{X}\right|\right)} \quad \text { (where } E D \text { is the edit dis- } \\
\text { tance of } t_{X} \text { and } s_{X} \text {, and }|t| \text { denotes the number of characters of } \\
t \text {.) }\end{array}$ \\
\hline & $f_{10}:$ & $\begin{array}{l}\text { character bigram similarity } \\
\text { of monolingual terms }\end{array}$ & $\begin{array}{l}f_{10}\left(t_{X}, s_{X}\right)=\frac{\operatorname{|bigram}\left(t_{X}\right) \cap \operatorname{bigram}\left(s_{X}\right) \mid}{\max \left(\left|t_{X}\right|,\left|s_{X}\right|\right)-1} \quad \text { (where } \operatorname{bigram}(t) \\
\text { is the set of character bigrams of the term } t \text {.) }\end{array}$ \\
\hline & $f_{11}:$ & $\begin{array}{l}\text { rate of identical morphemes } \\
\text { (for Japanese terms) }\end{array}$ & $\begin{array}{ll}f_{11}\left(t_{J}, s_{J}\right)=\frac{\left|\operatorname{const}\left(t_{J}\right) \cap \operatorname{const}\left(s_{J}\right)\right|}{\max \left(\left|\operatorname{consst}\left(t_{J}\right)\right|,\left|\operatorname{const}\left(s_{J}\right)\right|\right)} & \text { (where const }(t) \text { is } \\
\text { the set of morphemes in the Japanese term } t .) & \end{array}$ \\
\hline & $f_{12}:$ & $\begin{array}{l}\text { rate of identical characters } \\
\text { (for Chinese terms) }\end{array}$ & $\begin{array}{l}f_{11}\left(t_{C}, s_{C}\right)=\frac{\mid \operatorname{const}\left(t_{C}\right) \text { nconst }\left(s_{C}\right) \mid}{\max \left(\left|\operatorname{const}\left(t_{C}\right)\right|,\left|\operatorname{const}\left(s_{C}\right)\right|\right)} \quad(\text { where } \operatorname{const}(t) \text { is } \\
\text { the set of Characters in the Chinese term } t \text {.) }\end{array}$ \\
\hline & $f_{13}:$ & $\begin{array}{l}\text { subsumption relation of } \\
\text { strings / variants relation of } \\
\text { surface forms (for Japanese } \\
\text { terms ) }\end{array}$ & $\begin{array}{l}\text { returns } 1 \text { when the difference of } t_{J} \text { and } s_{J} \text { is only in their suffixes, } \\
\text { or only whether or not having the prolonged sound " } \iota \text { ", or only in } \\
\text { their hiragana parts. }\end{array}$ \\
\hline & $f_{14}:$ & $\begin{array}{l}\text { identical stem (for Chinese } \\
\text { terms) }\end{array}$ & $\begin{array}{l}\text { returns } 1 \text { when the difference of } t_{C} \text { and } s_{C} \text { is only whether or not } \\
\text { having the word "的" which is not the prefix or suffix. }\end{array}$ \\
\hline & $f_{15}:$ & $\begin{array}{l}\text { rate of intersection in trans- } \\
\text { lation by the phrase table }\end{array}$ & $\begin{array}{l}f_{15}\left(t_{X}, s_{X}\right)=\frac{\left|\operatorname{trans}\left(t_{X}\right) \cap \operatorname{trans}\left(s_{X}\right)\right|}{\max \left(\left|\operatorname{trans}\left(t_{X}\right)\right|,\left|\operatorname{trans}\left(s_{X}\right)\right|\right)} \quad \text { ( where } \operatorname{trans}(t) \\
\text { is the set of translation of term } t \text { from the phrase table.) }\end{array}$ \\
\hline & $f_{16}:$ & $\begin{array}{l}\text { rate of intersection in trans- } \\
\text { lation by the phrase table } \\
\text { (for the substrings not com- } \\
\text { mon between } t_{X} \text { and } s_{X} \text { ) }\end{array}$ & $\begin{array}{l}\text { Suppose that } x_{t}^{1}, \ldots, x_{t}^{m} \text { and } x_{s}^{1}, \ldots, x_{s}^{n} \text { are the substrings which } \\
\text { are not common between } t_{X} \text { and } s_{X} \text {. Here, we find } l(= \\
\min (m, n)) \text { pairs of one-to-one mappings between } x_{t}^{i}(i= \\
1, \ldots, m) \text { and } x_{s}^{j}(j=1, \ldots, n) \text { which maximize the product of } \\
\text { the rates } f_{15}\left(x_{t}^{i}, x_{s}^{j}\right) \text { of intersection in translation by the phrase ta- } \\
\text { ble and return this product. }\end{array}$ \\
\hline & $f_{17}:$ & $\begin{array}{l}\text { translation by the phrase ta- } \\
\text { ble }\end{array}$ & $\begin{array}{l}\text { returns } 1 \text { when } s_{J} \text { can be generated by translating } t_{C} \text { with the } \\
\text { phrase table, or, } s_{C} \text { can be generated by translating } t_{J} \text { with the } \\
\text { phrase table. }\end{array}$ \\
\hline
\end{tabular}

segmentation and $f_{2,3}+f_{6 \sim 9}+f_{11,12,15,16}$ for character-based segmentation, respectively. However, their differences are not significant $(5 \%$ significance level). Next, we evaluate the effect of each single feature as well as combinations of small number of features, where, among those results, Table 4 shows pairs of features each of which achieves a precision with no significant difference ( $5 \%$ significance level) with the set of features having the maximum precision. It is obvious that features $f_{15}$ and $f_{16}$, which utilize the rate of intersection in translation by the phrase table, are the most effective. Also, when we remove features $f_{15}$ and $f_{16}$ from all the features, precisions are significantly damaged (5\% significance level) to $78.5 \%$ and $79.4 \%$ for morpheme- based and character-based segmentations, respectively. The reason why these features are the most effective among other features is that they directly measure the degree of being synonymous within one language with respect to the rate of intersection of translations into the other language, while other features just measure the character-based or morpheme-based similarity within one language.

We further compare the performance of the proposed features with those studied in Tsunakawa and Tsujii (2008), where we modify the features of Tsunakawa and Tsujii (2008) as shown in Table 5 , and then evaluate those modified features. As we compare the performance of the proposed features and the modified features of Tsunakawa and Tsujii (2008) in Table 3, it is clear that the pro- 
Table 3: Evaluation Results (\%)

\begin{tabular}{|c|c|c|c|c|c|c|c|}
\hline & \multicolumn{3}{|c|}{ segmented by morphemes } & \multicolumn{3}{|c|}{ segmented by characters } \\
\hline & & precision & recall & f-measure & precision & recall & f-measure \\
\hline \multicolumn{2}{|c|}{$\begin{array}{l}\text { baseline ( } t_{J} \text { and } s_{J} \text { are identical, } \\
\text { or, } t_{C} \text { and } s_{C} \text { are identical.) }\end{array}$} & 71.4 & 40.0 & 51.3 & 74.0 & 40.1 & 52.0 \\
\hline \multirow{2}{*}{$\begin{array}{c}\text { SVM } \\
\text { (all features) }\end{array}$} & $\begin{array}{l}\text { maximum } \\
\text { precision }\end{array}$ & 86.5 & 26.5 & 40.5 & 89.0 & 26.1 & 40.4 \\
\hline & $\begin{array}{l}\text { maximum } \\
\text { f-measure }\end{array}$ & 64.3 & 64.1 & 64.2 & 63.5 & 65.3 & 64.4 \\
\hline $\begin{array}{c}\text { SVM } \\
\text { (features with } \\
\text { maximum precision) } \\
\end{array}$ & $\begin{array}{l}\text { maximum } \\
\text { precision }\end{array}$ & $\begin{array}{l}89.0 \\
\quad\left(f_{1}\right. \\
\end{array}$ & $\begin{array}{r}23.9 \\
6+f_{9} \\
\end{array}$ & $\begin{array}{r}37.7 \\
\sim 16) \\
\end{array}$ & $\begin{array}{c}90.4 \\
\left(f_{2,3}+f\right. \\
\end{array}$ & $\begin{array}{r}25.5 \\
\sim \\
\end{array}$ & $\begin{array}{c}40.4 \\
1,12,15,16) \\
\end{array}$ \\
\hline \multirow{2}{*}{$\begin{array}{l}\text { SVM (features in } \\
\text { Tsunakawa and } \\
\text { Tsujii (2008)) }\end{array}$} & $\begin{array}{l}\text { maximum } \\
\text { precision }\end{array}$ & 72.6 & 26.1 & 38.4 & 74.4 & 36.7 & 49.2 \\
\hline & $\begin{array}{l}\text { maximum } \\
\text { f-measure }\end{array}$ & 71.0 & 54.7 & 61.5 & 72.7 & 53.7 & 61.8 \\
\hline
\end{tabular}

Table 5: Features for Identifying Bilingual Synonymous Technical Terms by Tsunakawa and Tsujii (2008)

\begin{tabular}{|c|c|c|c|}
\hline class & \multicolumn{2}{|r|}{ features } & definition \\
\hline \multirow{7}{*}{$\begin{array}{l}\text { basical } \\
\text { features }\end{array}$} & $h_{1 J}, h_{1 C}:$ & $\begin{array}{l}\text { agreement of the first } \\
\text { characters }\end{array}$ & returns 1 when the fisrt characters of $t_{X}$ and $s_{X}$ match. \\
\hline & $h_{2 J}, h_{2 C}:$ & $\begin{array}{l}\text { edit distance of simi- } \\
\text { larity of monolingual } \\
\text { terms }\end{array}$ & the same as $f_{9}$ \\
\hline & $h_{3 J}, \quad h_{3 C}:$ & $\begin{array}{l}\text { character of bigram } \\
\text { similarity of monolin- } \\
\text { gual terms }\end{array}$ & the same as $f_{10}$ \\
\hline & $h_{4 J}, \quad h_{4 C}:$ & $\begin{array}{l}\text { agreement of word } \\
\text { substring }\end{array}$ & $\begin{array}{l}\text { return the count that substrings of } t_{X} \text { match } s_{X} \text {. (Here, Tsunakawa } \\
\text { and Tsujii (2008) count not only the common substrings but also } \\
\text { substrings in known synonymous relation between } t_{X} \text { and } s_{X} \text {. } \\
\text { However, in our work, we have no lexicon available for synonymous } \\
\text { relation. So, we utilize only the count of common substrings.) }\end{array}$ \\
\hline & $h_{5 J}, h_{5 C}:$ & $\begin{array}{l}\text { translation by the } \\
\text { phrase table }\end{array}$ & $\begin{array}{l}\text { the same as } f_{17} \text {. (Here, instead of the phrase table, Tsunakawa and } \\
\text { Tsujii (2008) utilize a bilingual lexicon and consider the existence } \\
\text { of bilingual lexical items as features. ) }\end{array}$ \\
\hline & & $\begin{array}{l}\text { identical stem for Chi- } \\
\text { nese terms }\end{array}$ & $\begin{array}{l}\text { the same as } f_{14} \text { (Although Tsunakawa and Tsujii (2008) define this } \\
\text { feature as examining the acronym relation of English terms, we } \\
\text { modify this feature as examining the difference of the Chinese terms } \\
\text { as the Chinese word "的".) }\end{array}$ \\
\hline & & $\begin{array}{l}\text { subsumption relation } \\
\text { of strings / variants } \\
\text { relation of surface } \\
\text { forms for Japanese } \\
\text { terms }\end{array}$ & $\begin{array}{l}\text { the same as } f_{13} \text { (Although Tsunanakwa and Tsujii (2008) examine } \\
\text { only the katakana variant, we additionally examine the difference } \\
\text { of suffixes and variants of hiragana parts.) }\end{array}$ \\
\hline & & $h_{1 J} \wedge h_{1 C}$ & - \\
\hline combina- & & $\sqrt{h_{2 J} \cdot h_{2 C}}$ & - \\
\hline torial & & $\sqrt{h_{3 J} \cdot h_{3 C}}$ & - \\
\hline feature & & $h_{5 J} \wedge h_{5 C}$ & - \\
\hline & & $h_{6} \cdot h_{2 J}$ & - \\
\hline & & $h_{7} \cdot h_{2 C}$ & - \\
\hline
\end{tabular}

posed features outperform the modified features of Tsunakawa and Tsujii (2008).

Next, Table 6 shows examples of improvement by SVM compared with the baseline. As shown in Table 6 (a), the relation between input bilingual term pairs and seed bilingual term pairs is correctly judged as "synonym", while judgement by the baseline is "not synonym" since neither the Chinese terms nor the Japanese terms are iden- tical. In our proposed features, $f_{17}$ contributes to the correct judgement, where it returns 1 because of the existence of the translation pairs /" ガラス転移温度”,“绝缘件”〉 and〈“ガラス転移 点”,“绝热体”〉 in the phrase table. In the case of another example shown in Table 6 (b), on the other hand, the proposed method correctly judges as "not synonym" by SVM compared with the baseline, where both the edit distance similarity 
Table 6: Examples of Improvement in Identifying Bilingual Synonymous Technical Terms by SVM

\begin{tabular}{|c|c|c|c|c|c|}
\hline Baseline: & \multicolumn{5}{|c|}{$\begin{array}{l}\text { Judge the input bilingual term pair }\left\langle t_{J}, t_{C}\right\rangle \text { as synonymous with the seed bilingual } \\
\text { term pair }\left\langle s_{J}, s_{C}\right\rangle \text { when } t_{J} \text { and } s_{J} \text { are identical, or, } t_{C} \text { and } s_{C} \text { are identical. } \\
\text { Maximize precision by tuning the lower bound of the confidence measure of the distance } \\
\text { from the separating hyperplane (Chinese sentences are segmented by morphemes). }\end{array}$} \\
\hline \multicolumn{6}{|c|}{ (a) Correct Judgement as "Synonym" only by SVM } \\
\hline \multicolumn{2}{|c|}{ seed $\left\langle s_{J}, s_{C}>\right.$} & $\begin{array}{l}\text { bilingual term pair } \\
\quad<t_{J}, t_{C}>\end{array}$ & $\begin{array}{l}\text { reference } \\
\text { judgement }\end{array}$ & $\begin{array}{l}\text { judgement } \\
\text { by baseline }\end{array}$ & $\begin{array}{l}\text { judgement } \\
\text { by SVM }\end{array}$ \\
\hline \multicolumn{2}{|c|}{$\begin{array}{c}\text { <グラス転移温度, 玻璃化转变温度> } \\
\text { (glass transition temperature) }\end{array}$} & $\begin{array}{c}\text { <グラス転移点, 玻璃态转化温度> } \\
\text { (glass transition temperature) }\end{array}$ & synonym & $\begin{array}{c}\text { not } \\
\text { synonym }\end{array}$ & synonym \\
\hline
\end{tabular}

(b) Correct Judgement as "Not Synonym" only by SVM

\begin{tabular}{|c|c||c|c|c|}
\hline seed $\left\langle s_{J}, \mathrm{~s}_{\mathrm{C}}>\right.$ & $\begin{array}{c}\text { bilingual term pair } \\
\left\langle t_{J}, t_{C}>\right.\end{array}$ & $\begin{array}{c}\text { reference } \\
\text { judgement }\end{array}$ & $\begin{array}{c}\text { judgement } \\
\text { by baseline }\end{array}$ & $\begin{array}{c}\text { judgement } \\
\text { by SVM }\end{array}$ \\
\hline $\begin{array}{c}<\text { 集電装置, 集电器> } \\
\text { (current collector) }\end{array}$ & $\begin{array}{c}<\text { コレクト(collector), } \\
\text { 集电器(current collector) })\end{array}$ & $\begin{array}{c}\text { not } \\
\text { synonym }\end{array}$ & synonym & $\begin{array}{c}\text { not } \\
\text { synonym }\end{array}$ \\
\hline
\end{tabular}

$\left(f_{9}\right)$ and the character bigram similarity $\left(f_{10}\right)$ between the Japanese terms “集電装置” and “コ レクト” are $0\left(f_{9}\left(\left\langle t_{J}, t_{C}\right\rangle,\left\langle s_{J}, s_{C}\right\rangle\right)=0\right.$ and $\left.f_{10}\left(\left\langle t_{J}, t_{C}\right\rangle,\left\langle s_{J}, s_{C}\right\rangle\right)=0\right)$.

Finally, Table 7 shows examples of erroneous judgements by SVM. As shown in Table 7 (a), since erroneous translation pairs 〈“断熱体”,“绝缘件”〉 and 〈“インシュレー ター”“绝热体”〉 exist in the phrase table, both $f_{17}$ (both of the translations pairs $\left\langle s_{J}, t_{C}\right\rangle$ and $\left\langle t_{J}, s_{C}\right\rangle$ exist in the phrase table) and $f_{17}$ (either the translation pair $\left\langle s_{J}, t_{C}\right\rangle$ or $\left\langle t_{J}, s_{C}\right\rangle$ exist in the phrase table) return 1 , resulting in erroneous judgement.

Another example is shown in Table 7 (b), where the proposed method returns erroneous judgement as "not synonym". In this case, since the translation pair〈“成膜チャンバー”“成膜室”〉 only exists in the phrase table, $f_{17}$ (either the translation pair $\left\langle s_{J}, t_{C}\right\rangle$ or $\left\langle t_{J}, s_{C}\right\rangle$ exist in the phrase table) returns 1 , while $f_{17}$ (both of translations pairs $\left\langle s_{J}, t_{C}\right\rangle$ and $\left\langle t_{J}, s_{C}\right\rangle$ exist in the phrase table) returns 0. Furthermore, even though Chinese words “成膜” and “膜成形” are synonymous, their character bigram similarity is computed as 0 , since they have opposite character orderings.

\section{Related Work}

Among related works on acquiring bilingual lexicon from text, Lu and Tsou (2009) and Yasuda and Sumita (2013) studied to extract bilingual terms from comparable patents, where, they first extract parallel sentences from comparable patents, and then extract bilingual terms from parallel sentences. Those studies differ from this paper in that those studies did not address the issue of acquiring bilingual synonymous technical terms. Tsunakawa and Tsujii (2008) is mostly related to our study, in that they also proposed to apply machine learning technique to the task of identifying bilingual synonymous technical terms. However, Tsunakawa and Tsujii (2008) studied the issue of identifying bilingual synonymous technical terms only within manually compiled bilingual technical term lexicon and thus are quite limited in its applicability. Our approach, on the other hand, is quite advantageous in that we start from parallel patent documents which continue to be published every year and then, that we can generate candidates of bilingual synonymous technical terms automatically. Furthermore, as we show in the previous section, the features proposed in this paper outperform that of Tsunakawa and Tsujii (2008).

\section{Conclusion}

In the task of acquiring Japanese-Chinese technical term translation equivalent pairs from parallel patent documents, this paper studied the issue of identifying synonymous translation equivalent pairs. This paper especially focused on the issue of examining the effectiveness of each feature and identified the minimum number of features that perform as comparatively well as the optimal set of features. One of the most important future work is definitely to improve recall. To do this, we plan to apply the semi-automatic framework (Liang et al., 2011b) which have been invented in the task of identifying Japanese-English synonymous translation equivalent pairs and have been proven to be effective in improving recall. Another important future work is to train the SVM of identifying bilingual synonymous technical pairs with a set 
Table 7: Examples of Errors in Identifying Bilingual Synonymous Technical Terms By the Proposed Method

(a) Incorrect Judgement as "Synonym" by SVM

\begin{tabular}{|c|c|c|c|c|c|c|c|c|c|}
\hline \multirow[b]{2}{*}{ seed $\left\langle s_{J}, s_{C}>\right.$} & \multirow[b]{2}{*}{$\begin{array}{l}\text { bilingual term pair } \\
\quad<t_{J}, t_{C}>\end{array}$} & \multicolumn{2}{|c|}{ for Japanese } & \multicolumn{2}{|c|}{ for Chinese } & \multirow{2}{*}{$\begin{array}{c}\text { feature } f_{17} \\
\text { (by translating with } \\
\text { the phrase table, } \\
\text { both } s_{J} \text { and } s_{C} \text { can } \\
\text { be generated from } \\
t_{C} \text { and } t_{J} \\
\text { respectively) }\end{array}$} & \multirow[b]{2}{*}{$\begin{array}{l}\text { feature } f_{17} \\
\text { (by translating with } \\
\text { the phrase table, } \\
s_{J} \text { or } s_{C} \text { can be } \\
\text { generated from } t_{C} \\
\text { or } t_{J} \text {, respectively) }\end{array}$} & \multirow[b]{2}{*}{$\begin{array}{l}\text { reference } \\
\text { judgement }\end{array}$} & \multirow[b]{2}{*}{$\begin{array}{c}\text { judgement } \\
\text { by SVM }\end{array}$} \\
\hline & & $\begin{array}{c}\text { feature } \\
f_{9}\end{array}$ & $\begin{array}{c}\text { feature } \\
f_{10}\end{array}$ & $\begin{array}{c}\text { feature } \\
f_{9}\end{array}$ & $\begin{array}{c}\text { feature } \\
f_{10}\end{array}$ & & & & \\
\hline $\begin{array}{c}\text { <断熱体, } \\
\text { 绝热体> } \\
\text { (heat insulator) }\end{array}$ & $\begin{array}{c}\text { <インシュレータ, } \\
\text { 绝缘件> } \\
\text { (insulator) }\end{array}$ & 0 & 0 & 0.33 & 0 & 1 & 1 & $\begin{array}{c}\text { not } \\
\text { synonym }\end{array}$ & synonym \\
\hline
\end{tabular}

(a) Incorrect Judgement as "Not Synonym" by SVM

\begin{tabular}{|c|c|c|c|c|c|c|c|c|c|}
\hline \multirow[b]{2}{*}{ seed $<s_{J}, s_{C}>$} & \multirow[b]{2}{*}{$\begin{array}{l}\text { bilingual term pair } \\
<t_{J}, t_{C}>\end{array}$} & \multicolumn{2}{|c|}{ for Japanese } & \multicolumn{2}{|c|}{ for Chinese } & \multirow{2}{*}{$\begin{array}{c}\text { feature } f_{17} \\
\text { (by translating with } \\
\text { the phrase table, } \\
\text { both } s_{J} \text { and } s_{C} \text { can } \\
\text { be generated from } \\
t_{C} \text { and } t_{J}, \\
\text { respectively) }\end{array}$} & \multirow{2}{*}{$\begin{array}{l}\text { feature } f_{17} \\
\text { (by translating with } \\
\text { the phrase table, } \\
s_{J} \text { or } s_{C} \text { can be } \\
\text { generated from } t_{C} \\
\text { or } t_{J} \text {, respectively) }\end{array}$} & \multirow[b]{2}{*}{$\begin{array}{l}\text { reference } \\
\text { judgement }\end{array}$} & \multirow[b]{2}{*}{$\begin{array}{c}\text { judgement } \\
\text { by SVM }\end{array}$} \\
\hline & & $\begin{array}{l}\text { feature } \\
\qquad f_{9}\end{array}$ & $\begin{array}{l}\text { feature } \\
\qquad f_{10}\end{array}$ & $\begin{array}{l}\text { feature } \\
\qquad f_{9}\end{array}$ & $\begin{array}{l}\text { feature } \\
\qquad f_{10}\end{array}$ & & & & \\
\hline
\end{tabular}

of patent families, and then to evaluate the trained SVM against parallel patent sentences and phrase tables extracted from another set of patent families.

\section{References}

A. Aker, M. Paramita, and R. Gaizauskas. 2013. Extracting bilingual terminologies from comparable corpora. In Proc. 51st ACL, pages 402-411.

P. Fung and L. Y. Yee. 1998. An IR approach for translating new words from nonparallel, comparable texts. In Proc. 17th COLING and 36th ACL, pages 414-420.

F. Huang, Y. Zhang, and S. Vogel. 2005. Mining key phrase translations from Web corpora. In Proc. HLT/EMNLP, pages 483-490.

P. Koehn, H. Hoang, A. Birch, C. Callison-Burch, M. Federico, N. Bertoldi, B. Cowan, W. Shen, C. Moran, R. Zens, C. Dyer, O. Bojar, A. Constantin, and E. Herbst. 2007. Moses: Open source toolkit for statistical machine translation. In Proc. 45th ACL, Companion Volume, pages 177-180.

G. Kontonatsios, I. Korkontzelos, J. Tsujii, and S. Ananiadou. 2014. Using random forest classifier to compile bilingual dictionaries of technical terms from comparable corpora. In Proc. 14th EACL, pages 111-116.
B. Liang, T. Utsuro, and M. Yamamoto. 2011a. Identifying bilingual synonymous technical terms from phrase tables and parallel patent sentences. Procedia - Social and Behavioral Sciences, 27:50-60.

B. Liang, T. Utsuro, and M. Yamamoto. 2011b. Semi-automatic identification of bilingual synonymous technical terms from phrase tables and parallel patent sentences. In Proc. 25th PACLIC, pages 196205.

Z. Long, L. Dong, T. Utsuro, T. Mitsuhashi, and M. Yamamoto. 2014. Identifying Japanese-Chinese bilingual synonymous technical terms from patent families. In Proc. 7th BUCC, pages 49-54.

B. Lu and B. K. Tsou. 2009. Towards bilingual term extraction in comparable patents. In Proc. 23rd PACLIC, pages 755-762.

Y. Matsumoto and T. Utsuro. 2000. Lexical knowledge acquisition. In R. Dale, H. Moisl, and H. Somers, editors, Handbook of Natural Language Processing, chapter 24, pages 563-610. Marcel Dekker Inc.

Y. Morishita, T. Utsuro, and M. Yamamoto. 2008. Integrating a phrase-based SMT model and a bilingual lexicon for human in semi-automatic acquisition of technical term translation lexicon. In Proc. 8th AMTA, pages 153-162.

R. Rapp and S. Sharoff. 2014. Extracting multiword translations from aligned comparable documents. In Proc. 3rd Workshop on Hybrid Approaches to Translation, pages 83-91. 
M. Tonoike, M. Kida, T. Takagi, Y. Sasaki, T. Utsuro, and S. Sato. 2006. A comparative study on compositional translation estimation using a domain/topicspecific corpus collected from the web. In Proc. 2nd Intl. Workshop on Web as Corpus, pages 11-18.

H. Tseng, P. Chang, G. Andrew, D. Jurafsky, and C. Manning. 2005. A conditional random field word segmenter for Sighan bakeoff 2005. In Proc. 4th SIGHAN Workshop on Chinese Language Processing, pages 168-171.

T. Tsunakawa and J. Tsujii. 2008. Bilingual synonym identification with spelling variations. In Proc. $3 r d$ IJCNLP, pages 457-464.

M. Utiyama and H. Isahara. 2007. A Japanese-English patent parallel corpus. In Proc. MT Summit XI, pages $475-482$.

V. N. Vapnik. 1998. Statistical Learning Theory. Wiley-Interscience.

K. Yasuda and E. Sumita. 2013. Building a bilingual dictionary from a Japanese-Chinese patent corpus. In Computational Linguistics and Intelligent Text Processing, volume 7817 of $L N C S$, pages 276284. Springer. 